\title{
Determination of the anisotropic fatigue behaviour of additively manufactured structures with short-time procedure PhyBaL $L_{L I T}$
}

\author{
Bastian Blinn ${ }^{1, *}$, Marcus Klein ${ }^{2}$, and Tilmann Beck ${ }^{1}$ \\ ${ }^{1}$ Institute of Materials Science and Engineering, TU Kaiserslautern, 67663 Kaiserslautern, Germany \\ ${ }^{2}$ State Materials Testing Institute Darmstadt (MPA), Chair and Institute for Materials Technology (IfW), Technische Universität \\ Darmstadt, 64283 Darmstadt, Germany
}

Key Words: Additive Manufacturing, load increase tests, $\mathrm{PhyBaL}_{\mathrm{LIT}}$, fatigue behaviour, anisotropy, 316L

\begin{abstract}
Additive Manufacturing techniques provide completely new possibilities in component design and creation of innovative material structures. To utilize the whole potential of Additive Manufacturing, the microstructure, the mechanical properties and their interrelations as well as their relationship to the Additive Manufacturing process parameters are essential. Investigations of the fatigue behaviour of additively manufactured (AM-) metallic materials are still available in limited extent. However, as a prerequisite for efficient and reliable use of AM-components in safety relevant structures, sound knowledge of fatigue behaviour and properties of these structures is indispensable. A central aspect in Additive Manufacturing is the anisotropic mechanical behaviour under monotonic and cyclic loading in dependency on the building direction $[1,2]$. In the present work, the microstructure and mechanical properties of Selective Laser Melted (SLM) as well as Laser Deposition Welded (LDW) AISI 316L stainless steel specimens are investigated with special focus on the influence of the building direction. The investigated specimens are built in horizontal and vertical direction, resulting in layer planes oriented parallel and perpendicular to the loading direction, respectively. The fatigue tests have been performed on a servohydraulic testing system with measurement of stress-strain-hysteresis as well as of plastic deformation induced changes in temperature and specific electrical resistance. S- $\mathrm{N}_{\mathrm{f}}$-curves in the HCF-regime of AM-specimens have been determined with the time and material efficient Physically Based Lifetime calculation procedure PhyBaLLIT [3]. Anisotropic fatigue behaviour of the different AM-specimens has been rated with load increase tests (LIT) and the usage of S- $\mathrm{N}_{f-}$ curves calculated by the PhyBaLLIT method.
\end{abstract}

\section{Introduction}

Within in the last decades, Additive Manufacturing underwent an extremely progressive development. This technology enables possibilities in manufacturing components far beyond the limits of conventional methods, such as casting or machining. Besides the possibility to realize complex structures, which can be optimized to their individual application, this technology opens the opportunity to locally modify materials properties of components during the manufacturing process [4].

To exploit the potential of this innovative manufacturing technology, it is necessary to investigate and understand the microstructure and the mechanical properties of additively manufactured (AM-) structures as well as the influence of the manufacturing parameters on materials properties.

One of the most important manufacturing parameters in Additive Manufacturing is the building direction, as already shown in many investigations of AM-materials, e.g. titanium alloys, aluminium alloys, nickel-base superalloys and stainless steels [1, 2, 5-9]. Especially the influence of the building direction on the monotonic mechanical properties have been investigated in a large extent $[1,2,5,6]$. In these investigations, the building direction in which the layer planes are perpendicular oriented to the loading direction (vertical building direction) show lower tensile strength compared to specimens with layer planes oriented parallel to the loading direction (horizontal building direction).

Currently, AM-components are mostly used in applications with minor safety requirements. To use this technique in safety relevant structural parts it is indispensable to get sound knowledge about the fatigue behaviour of AM-materials. Investigations about fatigue properties are available in a limited extent and, hence, a gap of knowledge in this field has to be closed. The investigations of Mower et al. on AISI 316L stainless steel [2], Shamseaeia et al. on Ti6Al4V [8] and Yadollahi et al. on 17-4-PH [1] show, according to the monotonic properties of AM-materials, an anisotropic fatigue behaviour depending on the building direction, i.e. a significantly higher fatigue strength of horizontally built specimens compared to the vertical building direction.

The production of AM-structures is, compared to conventional manufacturing, still relatively time and cost intensive, resulting in high efforts for characterization of the fatigue behaviour of AM-materials by typically 20 to 30 constant amplitude tests (CATs) to determine one S$\mathrm{N}_{\mathrm{f}}$ curve. To reduce this effort, short-time procedures 
based on load increase tests (LITs) and Physically Based Lifetime calculation $\mathrm{PhyBaL}_{\text {LIT }}$ [3] are considered especially useful in case of AM-structures.

In this work, the fatigue behaviour of Selective Laser Melted (SLM-) and Laser Deposition Welded (LDW-) specimens made of AISI 316L stainless steel built in horizontal (SLM-H, LDW-H) and vertical (SLM-V, LDW-V) direction were investigated. Additional to the results shown in Blinn et al. [10], LITs at a frequency of $2 \mathrm{~Hz}$ and lifetime calculations by the short-time procedure PhyBaL $\mathrm{LIT}_{\text {IT }}$ [3] were conducted. Therefore additionally to the LITs, CATs in the HCF-regime were performed. Based on the cyclic deformation curves of one LIT and two CATs of the differently manufactured specimens, $\mathrm{S}-\mathrm{N}_{\mathrm{f}}$-curves were calculated with the PhyBaL $_{\text {LIT }}$ method and verified by CATs. The anisotropic fatigue behaviour of AM-specimens were rated from the calculated $\mathrm{S}-\mathrm{N}_{\mathrm{f}}$-curves and additionally by the results of LITs.

\section{Materials}

The specimens were manufactured from AISI 316L stainless steel with the chemical composition, determined by spectrophotometric analyses, given in Table 1. The LDW-specimens exhibit significantly higher contents of chromium and nickel and lower content of nitrogen. These differences in chemical composition significantly influence austenite stability [11], which can be rated with the $\mathrm{M}_{\mathrm{d} 30}$-Temperatures determined from equation (1) according to Angel [12]. As shown in [10], austenite stability has to be taken in account for comparison of the mechanical properties of the differently manufactured specimens made of $316 \mathrm{~L}$, because lower austenite stability can result in higher deformation or stress induced transformation of the austenite into $\alpha$-martensite, which strongly influences the mechanical properties.

$$
M_{d 30, \text { Angel }}=413-462(C+N)-9.2 S i-8.1 M n-
$$

Table 1. Chemical compositions and $\mathrm{M}_{\mathrm{d} 30 \text {, Angel-temperatures of }}$ the different AM-specimens $[10,11]$

\begin{tabular}{|c|c|c|c|c|}
\hline $\begin{array}{l}\text { Amount of } \\
\text { alloying element } \\
\text { in wt.-\% }\end{array}$ & \multicolumn{2}{|c|}{ ASTM A 182 } & \multirow{2}{*}{ SLM } & \multirow{2}{*}{ LDW } \\
\cline { 2 - 3 } & Min & max & & \\
\hline $\mathbf{C}$ & -- & 0.03 & 0.02 & 0.03 \\
\hline $\mathbf{N}$ & -- & 0.10 & 0.08 & 0.10 \\
\hline $\mathbf{S i}$ & -- & 1.00 & 0.61 & 0.53 \\
\hline $\mathbf{M n}$ & -- & 2.00 & 1.44 & 1.30 \\
\hline $\mathbf{C r}$ & 16.00 & 18.00 & 17.68 & 16.41 \\
\hline $\mathbf{N i}$ & 10.00 & 15.00 & 13.07 & 10.54 \\
\hline $\mathbf{M o}$ & 2.00 & 3.00 & 2.26 & 2.04 \\
\hline $\mathbf{F e}$ & 60.80 & 72.00 & 64.68 & 68.75 \\
\hline $\mathbf{M}_{\mathbf{d} 30, \text { angel }}$ in ${ }^{\circ} \mathbf{C}$ & 61.8 & -117.1 & -58.3 & -28.5 \\
\hline
\end{tabular}

In the Additive Manufacturing processes blanks with a simple geometry were manufactured using the facilities and powders given in Table $2[10,11]$. To focus the investigations on properties of the volume microstructures, and to exclude the influence of surface topography, resulting from the Additive Manufacturing process, blanks were by subsequently turned to the final specimen geometry given in Fig. 1 and mechanically polished in the gauge length.

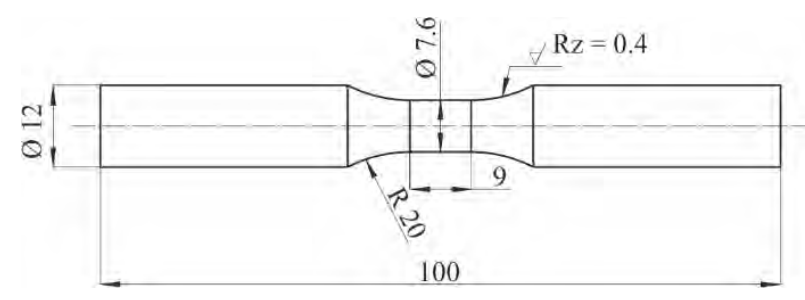

Fig. 1. Geometry of the fatigue specimens [10]

Table 2. Manufacturing parameters of the AM-blanks [10, 11]

\begin{tabular}{|l|c|c|}
\hline AM process & SLM & LDW \\
\hline Machine type & EOS M 290 & $\begin{array}{c}\text { DMG MORI } \\
\text { LASERTEC 65 3D }\end{array}$ \\
\hline Laser power in W & 400 & 2000 \\
\hline Powder size in $\boldsymbol{\mu m}$ & $25-45$ & $50-150$ \\
\hline $\begin{array}{l}\text { Av. Layer } \\
\text { thickness in } \boldsymbol{\mu m}\end{array}$ & 40 & 400 \\
\hline $\begin{array}{l}\text { Dimensions of the } \\
\text { blanks in mm }\end{array}$ & $\begin{array}{c}\text { bars } \\
\varnothing 14 \times 102\end{array}$ & $\begin{array}{c}\text { cuboids } \\
15 \times 15 \times 103\end{array}$ \\
\hline
\end{tabular}

\section{Experimental methods}

For investigation of the microstructure of the differently manufactured specimens, light optical micrographs (LOMs) of etched cross sections of the shafts of the fatigue specimens were taken with a Leica DM $6000 \mathrm{M}$ device. The SLM-specimens were etched using a V2A etchant, while LDW-specimens were etched with an Adler etchant, which results in better visualization of the grain structure in case of the higher chromium and nitrogen content of the LDW-specimens. Furthermore, scanning electron microscopy (SEM) observations were performed using a FEI Quanta 600 device.

The fatigue tests (LITs and CATs) were performed on a servo-hydraulic testing system with a stress ratio $\mathrm{R}=-1$ and a frequency of $\mathrm{f}=2 \mathrm{~Hz}$. The LITs were started at a stress amplitude of $\sigma_{\mathrm{a}}$, start $=100 \mathrm{MPa}$. The stress amplitude was then increased stepwise by $\Delta \sigma_{\mathrm{a}}=20 \mathrm{MPa}$ and a step length of 9000 cycles. Additionally for the LDW-specimens, modified LITs with a step length of 4 500 cycles and an increase of stress amplitude of $\Delta \sigma_{a}=10$ $\mathrm{MPa}$ were conducted to get a higher resolution in materials properties in the HCF-regime.

During the fatigue tests, stress-strain-hysteresis loops, the plastic deformation induced change in temperature and in electrical resistance according to Biallas et al. [13] were measured continuously. The experimental setup is shown in Fig. 2. Strain measurements were conducted with a conventional extensometer. The temperature was measured with one thermocouple in the gauge length $\left(\mathrm{T}_{1}\right)$ and two reference thermocouples at the elastically loaded shafts $\left(\mathrm{T}_{2}\right.$ and $\mathrm{T}_{3}$ ). The change in temperature was determined in according to equation (2), to compensate external influences on the specimen temperature. The change in temperature calculated this way results from the plastic 
deformation work dissipated in the gauge length volume of the specimen and, therewith, directly correlates with the area of the stress-strain-hysteresis loop in each cycle [13].

$$
\Delta T=T_{1}-\frac{T_{2}+T_{3}}{2}
$$

For Measurement of change in electrical resistance, a constant direct current of 8 A was applied to the specimen. The voltage drop was measured between two contact pins integrated in plastics clamps above and below the gauge length (see Fig. 2). The specific electrical resistance calculated from this according to Ohm's law is influenced by microstructural features such as dislocation density and dislocation structures, which makes this measurement sensitive to fatigue processes in the microstructure of the specimens [13].

Additionally, the content of the ferromagnetic fraction in the gauge length, was measured using a FERITSCOPETM MP 30E device before and after tensile and fatigue tests, to determine and quantify the amount of transformation from paramagnetic austenite into ferromagnetic $\alpha$-'martensite during monotonic and cyclic loading. This measurement is essential to determine the influence of the austenite stability on the mechanical properties.

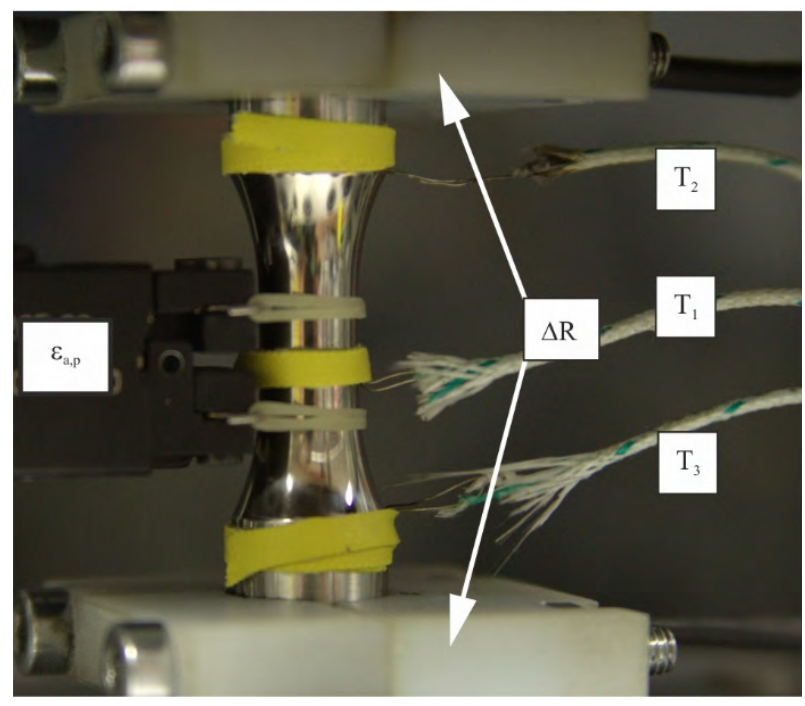

Fig. 2. Experimental setup of the fatigue tests [10]

\section{Results and Discussion}

\subsection{Microstructure and monotonic properties}

\subsubsection{Microstructure}

LOMs of the AM-specimens' microstructure show the layer boundaries along the building direction resulting from the additive manufacturing process (see Fig. $3 \mathrm{a}, \mathrm{f}$ and Fig. 4 a). The AM-microstructures also exhibit an elongation of grains along the building direction visible in LOMs and grain growth over the layer boundaries (see Fig. 3 a, f and Fig. 4 a), which is confirmed by electron backscatter diffraction (EBSD-) mappings (see Fig. $3 \mathrm{~b}$ and Fig. $4 \mathrm{~b}$ ). This unique grain structure results from the directed heat flux during the additive manufacturing process. This leads to a grain aspect ratio significantly $>1$, which also can be seen in lower apparent grain size in cross sections (CS)/ longitudinal sections (LS) of vertically/ horizontally built specimens compared to CS/LS of horizontally/ vertically built specimens (see Fig. 3 and Fig. 4).

LDW-specimens exhibit, compared to SLMspecimens bigger grains, which is caused by higher layer thickness (see Fig. 3 a, f, Fig. 4 a and Table 2), and therefore lower cooling rates in the manufacturing process.
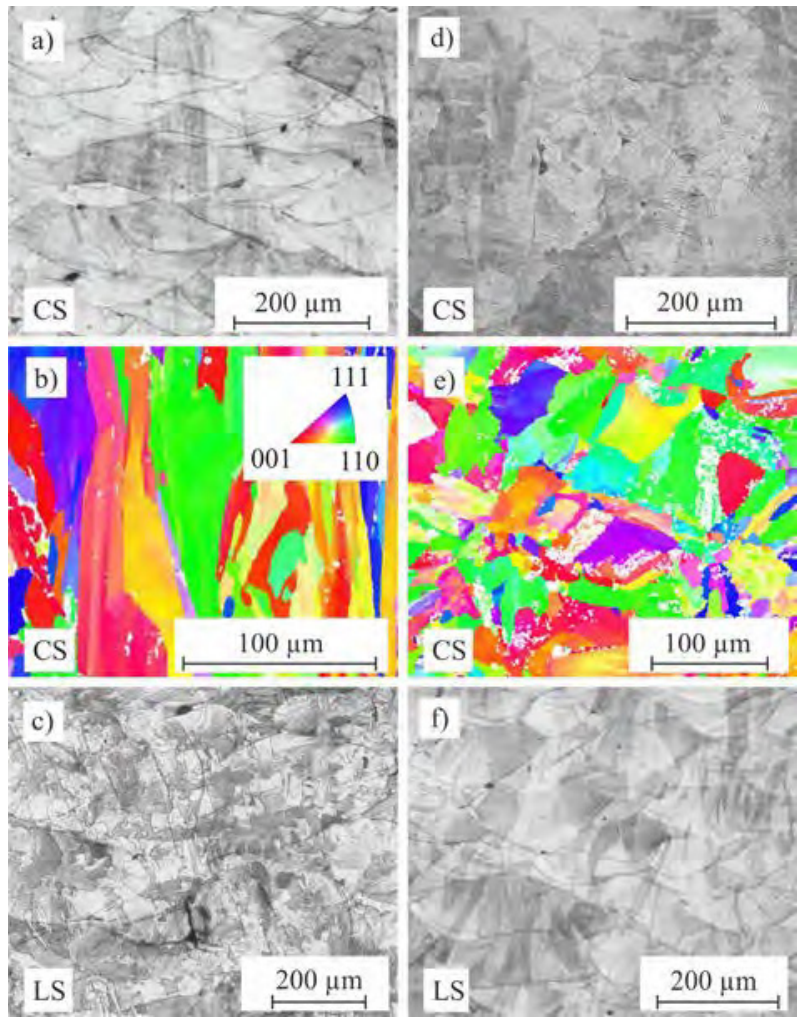

Fig. 3. LOMs of CS of a) SLM-H-, d) SLM-V-, LS of c) SLM$\mathrm{H}$ - and f) SLM-V- and EBSD-mappings of CS of b) SLM-Hand e) SLM-V -specimens [10]

Besides their unique grain structure, AM-materials exhibit defects like pores or oxide inclusions. Porosity of the differently manufactured specimens were rated by means of LOMs (see Table 3). SLM-specimens exhibit significantly higher porosities compared to LDWspecimens, which is caused by smaller layer thickness [14] and lower laser power [15] resulting in lower penetration depth of the laser in SLM-process. This leads to a higher amount of failure binding (see Fig. 5 a) and therefore higher porosity in SLM-material. SLM-V specimens exhibit lower porosity compared to SLM-Hspecimens, which may be caused by slight differences in manufacturing parameters and is not considered as a systematic difference between the microstructure of SLM-H- and SLM-V-specimens (comp. Fig. 3 a to $\mathrm{f}$ and c to d). 
Additionally to pores, the LDW-specimens exhibit silicon manganese (SiMn-) oxide inclusions [11] resulting from a partially incomplete protecting gas flow during manufacturing [16]. These oxide inclusions are bigger than pores in LDW-specimens (see Fig. 5 b), implying that oxide inclusions have a higher influence on fatigue strength in LDW-specimens.

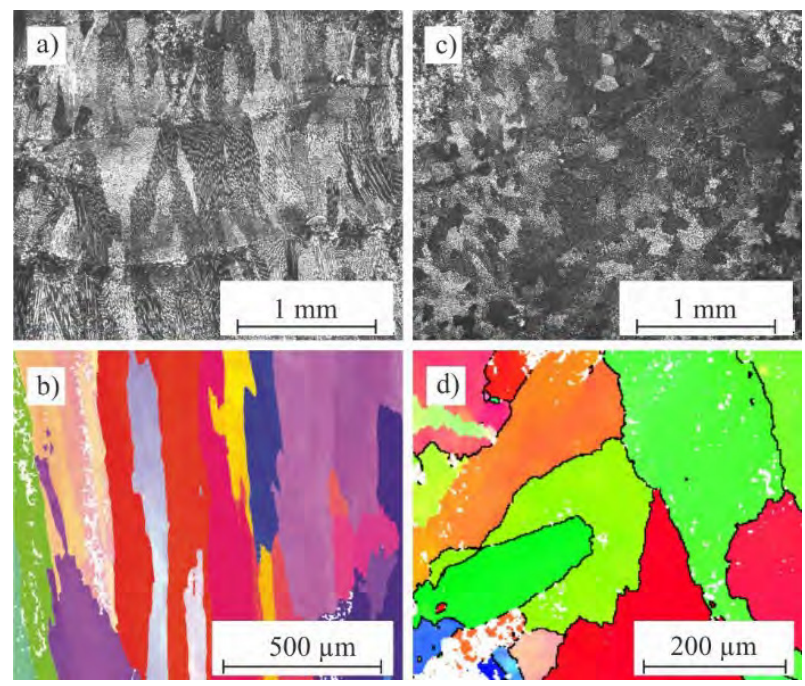

Fig. 4. LOMs of CS of a) LDW-H and c) LDW-V-, and EBSD-mappings of CS of b) LDW-H- and d) LDW-Vspecimens [10]
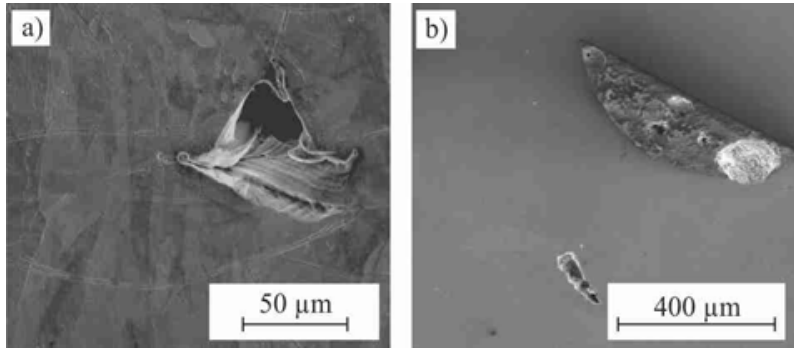

Fig. 5. SEM-image a) of a pore in SLM-material and b) of a pore and SiMn-oxide inclusion in LDW-material [10]

Table 3. Porosity and monotonic properties of AM-specimens [10]

\begin{tabular}{|l|c|c|c|c|}
\hline Specimen & SLM-H & SLM-V & LDW-H & LDW-V \\
\hline $\begin{array}{l}\text { Porosity } \\
\text { in \% }\end{array}$ & $\begin{array}{c}1.54 \\
\pm 0.49\end{array}$ & $\begin{array}{c}0.85 \\
\pm 0.27\end{array}$ & $\begin{array}{c}0.03 \\
\pm 0.01\end{array}$ & $\begin{array}{c}0.02 \\
\pm 0.01\end{array}$ \\
\hline $\mathbf{H V ~ 3 0 / 1 0}$ & 218 & 213 & 171 & 177 \\
\hline $\mathbf{R}_{\mathbf{m}}$ in MPa & $681 \pm 7$ & $612 \pm 2$ & $629 \pm 7$ & $564 \pm 9$ \\
\hline $\begin{array}{l}\mathbf{R}_{\mathrm{p} 0.2} \text { in } \\
\text { MPa }\end{array}$ & $609 \pm 43$ & $490 \pm 2$ & $438 \pm 40$ & $322 \pm 2$ \\
\hline $\begin{array}{l}\text { Young's } \\
\text { Modulus } \\
\text { in GPa }\end{array}$ & $167 \pm 12$ & $152 \pm 7$ & $172 \pm 12$ & $170 \pm 10$ \\
\hline \begin{tabular}{l}
$\mathbf{A}$ in \% \\
\hline $\begin{array}{l}\boldsymbol{\Delta} \text { in } \\
\text { Fe-\% }\end{array}$
\end{tabular} & 28.9 & $\begin{array}{c}21.4 \\
\pm 1.6\end{array}$ & $\begin{array}{c}37.8 \\
\pm 0.3\end{array}$ & $\begin{array}{c}26.8 \\
\pm 4.9\end{array}$ \\
\hline
\end{tabular}

\subsubsection{Monotonic properties}

Results of tensile tests are given in Table 3 and show an anisotropic behaviour of AM-specimens in dependency of the building direction in accordance to [1, $2,5,6]$. Horizontally built specimens show higher tensile strength, $0.2 \%$ yield stress and elongation at fracture compared to vertical building direction. In elastic properties, i.e. young's modulus, no significant influence of building direction or manufacturing process occurs.

In contrast to tensile tests, Vickers (HV30) hardness measurements do not show anisotropic properties depending on the building direction. The SLMspecimens possess higher tensile and $0.2 \%$ yield stress compared to LDW-specimens, which correlates to the hardness values and results from higher cooling rates associated with smaller layer size in case of SLM (see Table 2). The elongation at fracture of LDW-specimens is higher compared to SLM-specimens with the same building direction. This correlates to $\Delta \xi$-measurements (see Table 3), which indicate lower austenite stability of the LDW-specimens (also see Table 1). This results show, that austenite- $\alpha$ '-martensite transformation and, hence, austenite stability influences the mechanical properties of the investigated AISI 316L variants.

\subsection{Fatigue behaviour}

\subsubsection{Load increase tests (LITs)}

The fatigue behaviour of the AM-specimens was determined by evaluation of three key results of LITs: The shape of cyclic deformation curves, the last load step of linear growth of materials reaction $\sigma_{1}$ and the load step at failure $\sigma_{\mathrm{f}}$, The cyclic deformation curves in LITs show in the first load steps a linear growth of the measured quantities. Afterwards, all specimens show in an individual load step a transition to significant plastic deformation, followed by progressive growth of materials reaction (see Fig. $6 \mathrm{c}$ ). The last load step before this transition is defined as $\sigma_{1}$ and is used as reference for fatigue behaviour at lower stress amplitudes, while $\sigma_{\mathrm{f}}$ is used as reference at higher stress amplitudes.
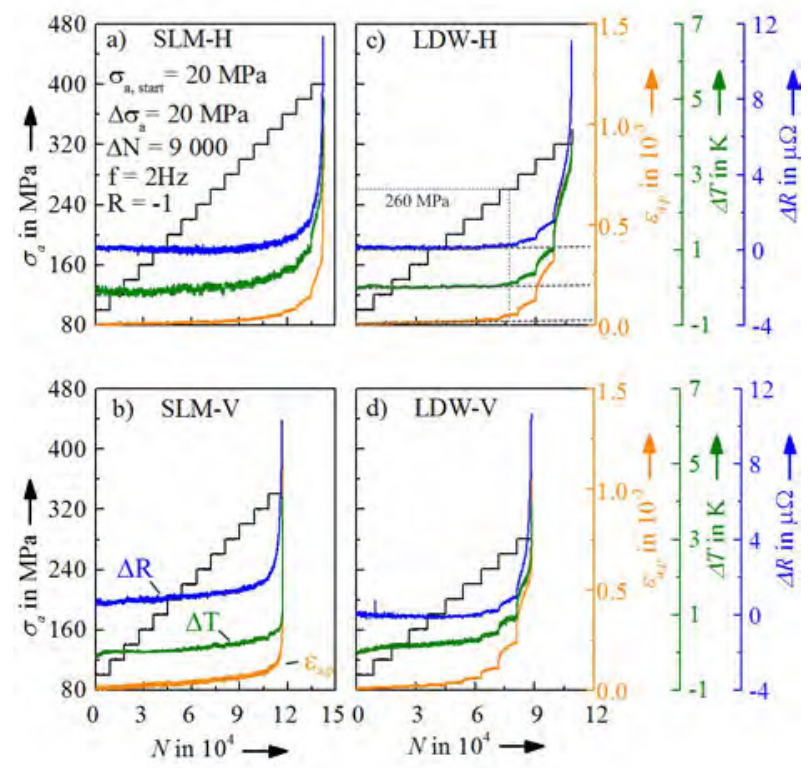
Fig. 6. Cyclic deformation behaviour of AM-specimens obtained by LITs with measurements of plastic strain amplitude $\left(\varepsilon_{\mathrm{a}, \mathrm{p}}\right)$, change in temperature $(\Delta \mathrm{T})$ and electrical resistance $(\Delta R)$, and a schematic description in c) of determination of $\sigma_{1}$

Table 4. Results of $\sigma_{\mathrm{l}}, \sigma_{\mathrm{f}}$ and $\Delta \xi$ for different AM-specimens in LITs

\begin{tabular}{|l|c|c|c|c|}
\hline Specimen & SLM-H & SLM-V & LDW-H & LDW-V \\
\hline $\boldsymbol{\sigma}_{\mathbf{l}}$ in MPa & 280 & 240 & 240 & 200 \\
\hline $\boldsymbol{\sigma}_{\mathbf{f}}$ in MPa & 400 & 360 & 340 & 280 \\
\hline $\begin{array}{l}\Delta \boldsymbol{\xi} \text { in } \\
\text { Fe-\% }\end{array}$ & 0.0 & 0.0 & 0.2 & 0.1 \\
\hline
\end{tabular}

Note that the different measured quantities show identical load steps at first significant plastic deformation processes for each type of specimen.

The results of LITs given in Table 4 show an anisotropic fatigue behaviour of AM-specimens. Vertically built specimens show lower values of $\sigma_{1}$ and $\sigma_{\mathrm{f}}$ and higher $\varepsilon_{\mathrm{a}, \mathrm{p}}$ at identical load amplitude compared to horizontal building direction and, hence, similar to monotonic properties, lower performance in LITs in accordance to results of $[1,2,8]$.

In contrast to SLM-specimens, the LDW-specimens show an increase of magnetic fraction in the gauge length after LIT, which is caused by the lower austenite stability (see Table 1 and Table 4), resulting in austenite$\alpha^{\prime}$-martensite-transformation. However by comparison of the same building direction, SLM-specimens show higher fatigue performance in LITs compared to LDWspecimens, identifiable by higher values of $\sigma_{\mathrm{f}}$ and $\sigma_{\mathrm{l}}$. Moreover, the LDW-specimens show higher plastic deformation compared to SLM-specimens with the same building direction.

\subsubsection{S- $N_{f}$-curves determined with PhyBaL $L_{L I T}$}

The fatigue strength of the different AM-specimens in the HCF-regime is compared based on results of CATs and $\mathrm{S}-\mathrm{N}_{\mathrm{f}}$-curves calculated by the short-time procedure $\mathrm{PhyBaL}_{\mathrm{LIT}}$. In this approach, the slope of the $\mathrm{S}-\mathrm{N}_{\mathrm{f}}$-curves is calculated based on the cyclic deformation behaviour. For this, Basquin's law [17] (see equation (3)) is combined with Morrow's correlation between the slope of S- $\mathrm{N}_{\mathrm{f}}$-curves in the HCF-regime, represented by the fatigue strength exponent $b$, and the cyclic hardening exponent $n$ ' of cyclic hardening curves $\left(\sigma_{a}-\varepsilon_{a, p}\right.$-curves, see equation (5)) [18]. The cyclic hardening curves can be described by the power law given in equation (4) with the cyclic hardening coefficient $\mathrm{K}$ ' and cyclic hardening exponent n'.

$$
\begin{gathered}
\sigma_{a}=\sigma_{f}^{\prime}\left(2 N_{f}\right)^{b} \\
\sigma_{a}=K^{\prime} \cdot \varepsilon_{a, p}^{n^{\prime}} \\
b=\frac{-n^{\prime}}{5 n^{\prime}+1}
\end{gathered}
$$

The PhyBaL $L_{\text {LIT }}$ method allows calculating of an S- $\mathrm{N}_{\mathrm{f}^{-}}$ curve based on only three fatigue tests, which means a significant reduction of experimental effort: One load increase test is performed to characterize cyclic deformation behaviour under different load amplitudes with one specimen. Based on the LIT results, the stress amplitude for two different constant amplitude tests (CATs) is determined: One CAT is conducted at high stress amplitude below the load step of failure in the LIT and the other CAT is performed at a low stress amplitude, in which plastic deformation already occurs (see Fig. 7).

To determine the cyclic hardening curve, the mean values of $\varepsilon_{\mathrm{a}, \mathrm{p}}$ in all load steps of LIT between the stress levels of the two CATs are determined and plotted in a $\sigma_{a}-\varepsilon_{a, p}$-diagram (see Fig. 7). Note that in most cases the cyclic hardening curve directly taken from the LIT cannot be used for lifetime calculation, because the materials reaction in the load steps with higher stress amplitudes are influenced by previous fatigue processes at lower stress amplitudes and therefore do not represent the materials behaviour for constant amplitude fatigue loading. To increase the data density of the $\sigma_{\mathrm{a}}-\varepsilon_{\mathrm{a}, \mathrm{p}}$-curves for constant amplitude loading, the mean $\varepsilon_{\mathrm{a}, \mathrm{p}}$ values of the single LIT load steps are then transferred by interpolation to constant amplitude values based on the values of $\varepsilon_{a, p}$ at the half of lifetime $\left(\mathrm{N}_{\mathrm{f}} / 2\right)$ of each CAT (see Fig. 7). Based on the resulting cyclic hardening curve, the cyclic hardening exponent n' and, with equation (5), the slope of $\mathrm{S}-\mathrm{N}_{\mathrm{f}}$-curve $\mathrm{b}$ can be determined.

To determine the position of the S- $\mathrm{N}_{\mathrm{f}}$-curve, $\sigma_{\mathrm{a}}$ and $\mathrm{N}_{\mathrm{f}}$ of the CAT at higher stress amplitude is inserted in equation (3) and the fatigue strength coefficient $\sigma_{\mathrm{f}}$ of the $\mathrm{S}-\mathrm{N}_{\mathrm{f}}$-curve is calculated. The CAT at higher stress amplitude is chosen for determination of $\sigma_{\mathrm{f}}$ to minimize the influence of lifetime scatter, which is higher at lower stress amplitudes in HCF-regime.
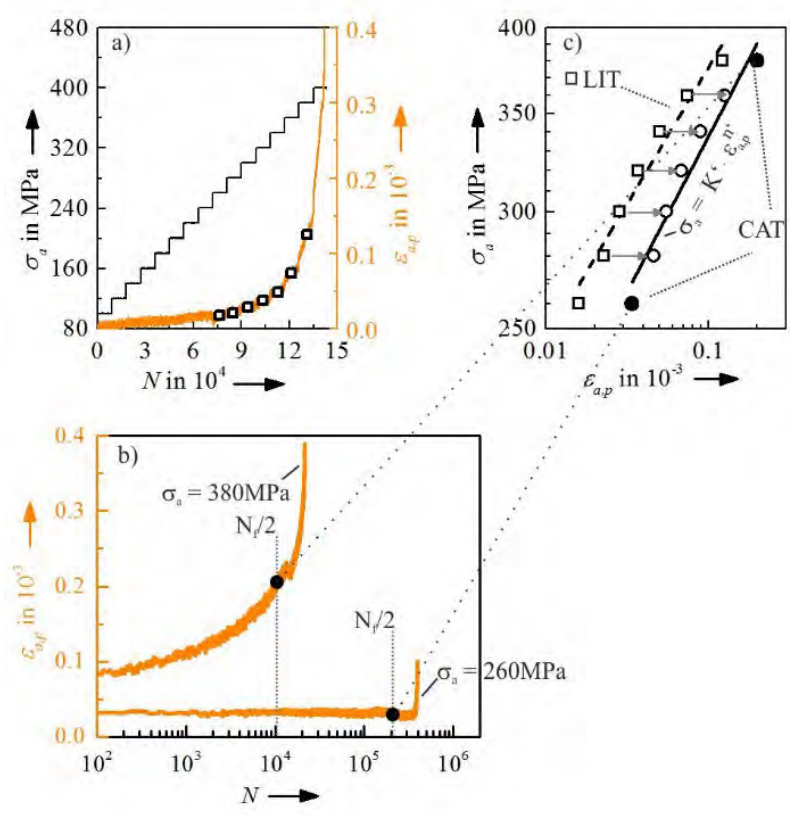
Fig. 7. Description of the short-time procedure PhyBaL $_{\text {LIT }}$ with results of $\varepsilon_{\mathrm{a}, \mathrm{p}}$ measurements of SLM-H-specimens

The cyclic deformation curves of the different AMspecimens used for calculation of the $\mathrm{S}-\mathrm{N}_{\mathrm{f}}$-curves by the PhyBaL $_{\text {LIT }}$ method are given in Fig. 8 a, b, d and e. The test parameters of LITs for LDW-specimens differ slightly compared to those used in case of SLMspecimens: Due to the relatively low stress amplitude range between onset of first materials reaction and specimen failure, the CATs, resulting out of LITs in Fig. $6 \mathrm{c}$ and $\mathrm{d}$, lead to a cyclic hardening curve with a relatively small amount of data. Therefore, additional LITs were performed with a reduced step length of 4500 cycles and a load increase of only $10 \mathrm{MPa}$ to enhance resolution at $\mathrm{HCF}$ - relevant stress amplitudes. These modified LITs were started for the LDW-V-specimens at a stress amplitude of $\sigma_{\mathrm{a}, \text { start }}=120 \mathrm{MPa}$ and for LDW-Lspecimens of $\sigma_{\mathrm{a} \text {, start }}=180 \mathrm{MPa}$.

The stress amplitudes of the "high stress" CATs for SLM-H- and LDW-V-specimens were determined as the last load step below $\sigma_{\mathrm{f}}$. The SLM-V- and LDW-Hspecimens fail in LITs after a low number of cycles in the last load step. Hence, to avoid influence of crack growth, a stress amplitude two steps below $\sigma_{\mathrm{f}}$ is determined for the "high stress" CAT. For CATs at lower stress amplitude, stress amplitudes with indications of microplastic deformation in the LIT, but below the transition area to significant plastic deformation were used.
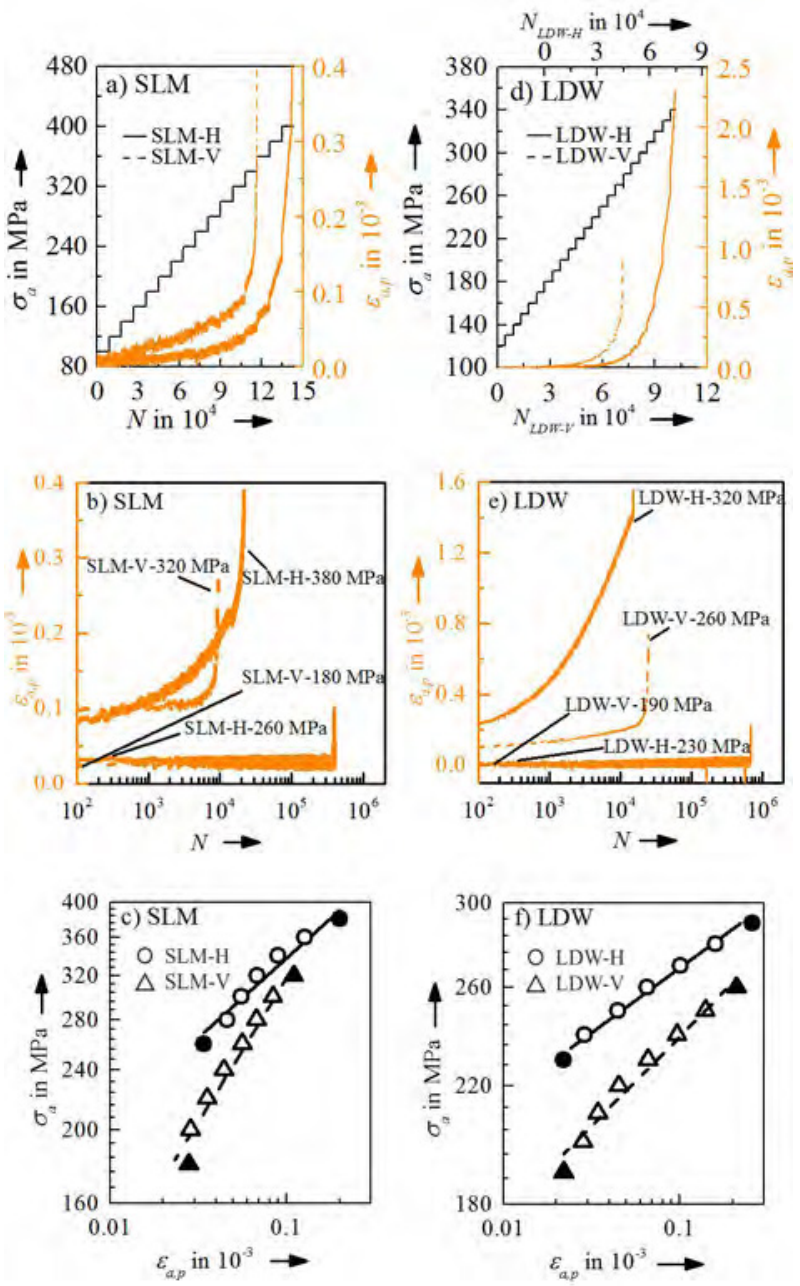

Fig. 8. Cyclic deformation curves with measurements of $\varepsilon_{a, p}$ in LIT in a) and d) and in CATs in b) and e) for PhyBaL LIT method and resulting $\sigma_{\mathrm{a}}-\varepsilon_{\mathrm{a}, \mathrm{p}}$-curves in c) and f)

The resulting cyclic hardening curves show a high coefficient of determination $\mathrm{R}^{2}$ and are hence considered appropriate for calculation of the cyclic hardening exponent n' (see Table 5). The $\mathrm{S}-\mathrm{N}_{\mathrm{f}}$-curves calculated by PhyBaL $_{\text {LIT }}$ and shown in Fig. 9, are in good accordance with the data of additional CATs in the HCF-regime. Similar to the $\mathrm{S}-\mathrm{N}_{\mathrm{f}}$-curves shown in [10], the $\mathrm{S}-\mathrm{N}_{\mathrm{f}}$ curves for vertically built specimens show a slightly steeper slope compared to horizontal building direction (see Fig. 9 and Table 5). This anisotropic fatigue behaviour correlates to the results of LITs and CATs, which show for SLM- and LDW-specimens higher fatigue strength in horizontal building direction (see Fig. 6 and Fig. 9) in accordance to $[1,2,8]$.

Comparing the different manufacturing processes in identical building directions, SLM-specimens show higher lifetime at high stress amplitudes but lower lifetime at low stress amplitudes compared to LDWspecimens, which can also be seen in the calculated slopes of $\mathrm{S}-\mathrm{N}_{\mathrm{f}}$-curves (see Fig. 9 and Table 5). The flatter slope in $\mathrm{S}-\mathrm{N}_{\mathrm{f}}$-curves of $\mathrm{LDW}$-specimens is influenced by lower austenite stability of the LDWmaterial, leading to austenite- $\alpha$ '-martensitetransformation during CATs. This transformation of austenite into $\alpha$-martensite does not lead to cyclic 
hardening in cyclic deformation curves of LDWspecimens as can be seen in Fig. 8 and, hence, seems to be a locally restricted process in highly stressed regions at microstructural defects leading to a higher lifetime, especially at lower stress amplitudes (see Fig. 9) [19, 20]. These results show, that for characterisation of fatigue properties of the AISI 316L stainless steel, the austenite stability and, hence, chemical composition has to be taken in account.

Table 5. S- $\mathrm{N}_{\mathrm{f}}$-curve parameters in HCF-regime of AMspecimens calculated by means of $\mathrm{PyBaL}_{\mathrm{LIT}}$ and CAT data for verification

\begin{tabular}{|l|c|c|c|c|}
\hline Specimen & SLM-H & SLM-V & LDW-H & LDW-V \\
\hline $\mathbf{n}^{\prime}$ & 0.220 & 0.392 & 0.082 & 0.135 \\
\hline $\mathbf{B}$ & -0.105 & -0.132 & -0.058 & -0.081 \\
\hline $\boldsymbol{\sigma}_{\mathbf{f}}$ & 1165 & 1180 & 627 & 622 \\
\hline $\mathbf{R}^{\mathbf{2}}$ & 0.96 & 0.96 & 0.99 & 0.98 \\
\hline
\end{tabular}

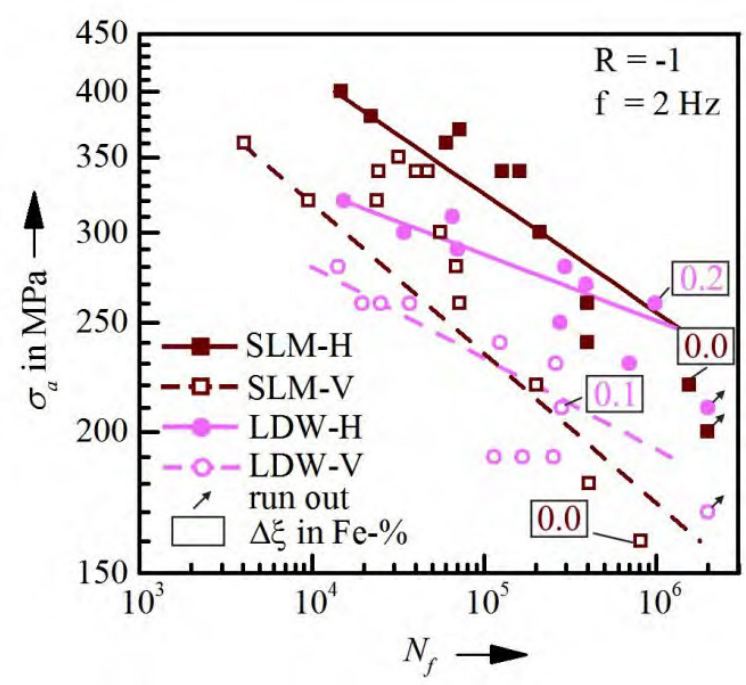

Fig. 9. S- $\mathrm{N}_{\mathrm{f}}$-curves calculated by means of $\mathrm{PhyBaL}_{\mathrm{LIT}}$ and experimental data of CATs

The scatter in S- $\mathrm{N}_{\mathrm{f}}$-curves is caused by microstructural defects described in section 4.1.1 which correlates with investigations of Günther et al. [21] at Ti6Al4V and Mower et al. [2] at AISI 316L stainless steel. In SLM-specimens the size and distance of crack initiating pores to the surface affect the scatter in $\mathrm{S}^{-\mathrm{N}_{\mathrm{f}}}$ curves (see Fig. 10 a). In LDW-specimens, different locations, shape and size of oxide inclusions lead to scatter in lifetime while the relatively small and few pores in LDW-material are assumed not to influence fatigue lifetime significantly (see Fig. 10 b).

The SLM-V-specimens have lower porosity compared to SLM-H-specimens (see Table 3). However, horizontally built specimens show lower lifetime scatter (comp. [10]). In correlation to SLM-material, horizontally built specimens show lower scatter compared to vertical building direction in LDWmaterial. Hence, the horizontally built AM-specimens seem to have higher capability to reduce locally increased stresses at microstructural defects. This correlates to the higher plasticity at fracture in tensile tests (see Table 3 ) and higher plastic strain amplitude in last load steps in LIT of horizontally built specimens compared to vertical building direction respectively.
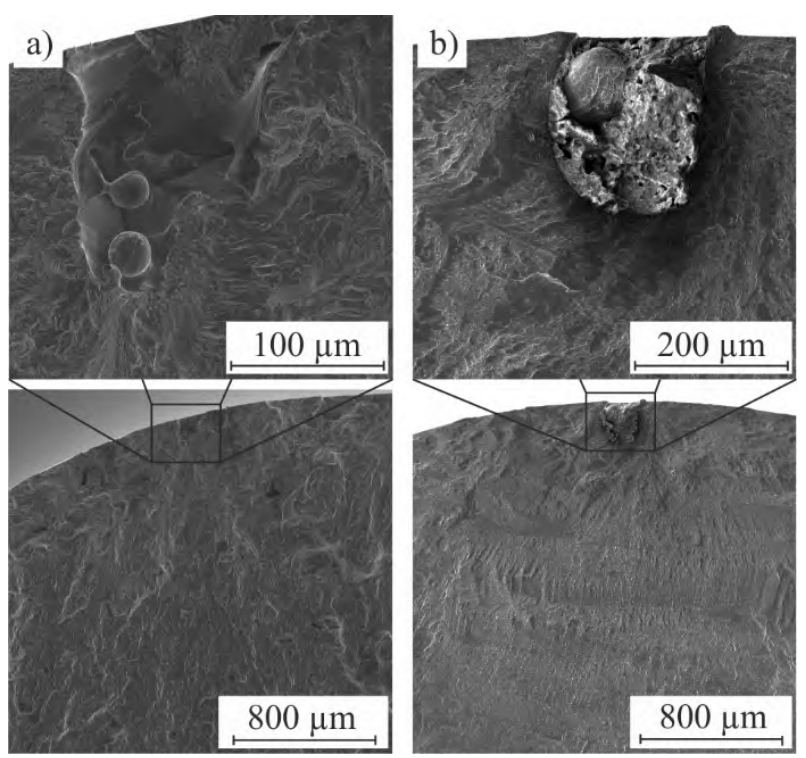

Fig. 10. Fracture surface of a) SLM-H-specimen $\left(\sigma_{\mathrm{a}}=\right.$ $300 \mathrm{MPa} ; \mathrm{N}_{\mathrm{f}}=212218$ ) with crack initiation at a pore and b) LDW-H-specimen $\left(\sigma_{\mathrm{a}}=260 \mathrm{MPa} ; \mathrm{N}_{\mathrm{f}}=982098\right)$ with crack initiation at a SiMn-oxide inclusion [10]

\section{Summary and conclusion}

Specimens manufactured by Selective Laser Melting (SLM) and Laser Deposition Welding (LDW) made of AISI 316L stainless steel were investigated with regard to their microstructure and mechanical properties. Focus of the investigations was to determine the influence of the building direction on fatigue behaviour of these additively manufactured (AM-) specimens by means of short-time procedures, i.e. load increase tests (LITs) and PhyBaL LIT $_{\text {. }}$.

The microstructure of AM-specimens exhibit grain elongation along the building direction and grain growth over the layer boundaries visible in light optical micrographs. Furthermore, the AM-materials exhibit microstructural inhomogeneities, i.e. pores in both AMmaterials and SiMn-oxide inclusions in LDW-material. In SLM-material pores and in LDW-material oxide inclusions, which are bigger compared to the pores in LDW-materials, are determined to cause scatter in fatigue lifetime.

Monotonic properties of AM-specimens show anisotropic behaviour, i.e. higher elongation at fracture, tensile strength and $0.2 \%$ yield stress in horizontal building direction compared to vertically built specimens. Further, in the same building direction, the SLM-specimens show higher tensile strength and $0.2 \%$ yield stress compared to LDW-specimens and lower elongation at fracture, which correlates to higher amount of austenite- $\alpha^{\prime}$-martensite-transformation resulting from lower austenite stability in LDW-material.

The LITs show anisotropic fatigue behaviour of AMspecimens, which is confirmed by results of constant amplitude tests (CATs) and $\mathrm{S}-\mathrm{N}_{\mathrm{f}}$-curves calculated by means of PhyBaL $L_{L I T}$. The result of lifetime calculation 
are in good accordance to the CATs. Horizontally built specimens from both manufacturing processes show higher fatigue strength, lower amount of scatter and a slightly flatter slope of the $\mathrm{S}-\mathrm{N}_{\mathrm{f}}$-curves.

By comparison of the fatigue behaviour of the different Additive Manufacturing processes for identical building direction, the LDW-specimens show higher lifetime at lower stress amplitudes and lower lifetime at higher stress amplitudes than SLM-specimens. This is influenced by austenite- $\alpha$ '-martensite-transformation in LDW-material, which leads to higher lifetime especially at lower stress amplitudes and shows, that austenite stability and, hence, chemical composition significantly influences the fatigue properties of AISI $316 \mathrm{~L}$ stainless steel.

The results demonstrate, that the short-time procedures LIT and $\mathrm{PhyBaL}_{\text {LIT }}$ can be used to determine the fatigue behaviour of AM-specimens. With LIT the anisotropic fatigue behaviour can be described very efficiently and, hence, this method can be used for investigations of the influence of variations in manufacturing parameters or post processing on anisotropic fatigue behaviour. $\mathrm{PhyBaL}_{\mathrm{LIT}}$ proved to be a viable method to determine fatigue strength in dependency on AM-process and building direction very efficiently.

The LIT cannot determine the influence of austenite$\alpha$ '-martensite-transformation at lower stress amplitudes, because the low number of cycles in the LIT do not lead to deformation induced phase transformation at lower stress amplitudes. However phase transformation in CATs reduces the amount of local plastic deformation at microstructural defects, especially at lower stress amplitudes, leading to a flatter $\sigma_{\mathrm{a}}-\varepsilon_{\mathrm{a}, \mathrm{p}}$-curve, which influences the slope of $\mathrm{S}-\mathrm{N}_{\mathrm{f}}$-curve. Hence, with the PhyBaL $_{\text {LIT }}$ method the influence of phase transformation can be determined due to the additional information of CATs, if phase transformation is locally restricted at microstructural defects.

\section{Acknowledgement}

The research described in this paper was done in collaboration to the Institute for Manufacturing Technology and Production System at the University of Kaiserslautern and was financially supported by European Union's European Regional Development Fund (ERDF) and the Commercial Vehicle Cluster (CVC) Südwest.

\section{References}

1. A. Yadollahi, N. Shamsaei, S. M. Thompson, A. Elwany, L. Bian: Int J Fatigue, Effects of building orientation and heat treatment on fatigue behavior of selective laser melted 17-4 PH stainless steel. 94: p. 218-235, (2017).

2. T. M. Mower, M. J. Long: Mater Sci Eng A, Mechanical behavior of additive manufactured, powder-bed laser-fused materials. 651: p. 198213, (2016).
3. H. S. Kramer, P. Starke, M. Klein, D. Eifler: Int. J. Fatigue, Cyclic hardness test PHYBALCHT - Short-time procedure to evaluate fatigue properties of metallic materials. 63: p. 78-84, (2014).

4. S.R. Daniewicz, N. Shamsaei: Int J Fatigue, $A n$ introduction to the fatigue and fracture behavior of additive manufactured parts. 94: $\mathrm{p}$. 167, (2017).

5. J. J. Lewandowski, M. Seifi: Annu Rev Mater Res, Metal Additive Manufacturing: A Review of Mechanical Properties. 46: p. 151-186, (2016).

6. R. Casati, J. Lemke, M. Vedani: J Mater Sci Technol: Microstructure and Fracture Behavior of 316L Austenitic Stainless Steel Produced by Selective Laser Melting. 32: p. 738-744, (2016).

7. T. Bauer, K. Dawson, A.B. Spierings, K. Wegener: 26th Annual International Solid Freeform Fabrication (SFF) Symposium: Microstructure and mechanical characterisation of SLM processed Haynes ${ }^{\circledR}$ $230 \circledR$. (2015)

8. N. Shamsaeia, A. Yadollahi, L. Bian, S. M. Thompson: ADDMA, An overview of Direct Laser Deposition for additive manufacturing;Part II: Mechanical behavior, process parameter optimization andcontrol. $\mathbf{8}$ : p. 12-35, (2015).

9. E. Brandl, C.Leyens, F. Palm: IOP Conf. Series: Materials Science and Engineering 26, Mechanical properties of additive manufactured Ti-6Al-4V using wire and powder based processes., 26, (2011).

10. B. Blinn, M. Klein, C. Gläßner, M. Smaga, J. C. Aurich, T. Beck: Metals, Investigation of microstructure and fatigue behavior of additively manufactured AISI $316 \mathrm{~L}$ stainless steel with regard to the influence of a heat treatment. (2018) (accepted).

11. C. Gläßner, B. Blinn, M. Burkhart, M. Klein, T. Beck, J. C. Aurich: 7. WGP Jahreskongress, Comparison of $316 \mathrm{~L}$ test specimens manufactured by Selective Laser Melting, Laser Deposition Welding and Continuous Casting. Aachen: Apprimus Verlag, (2017).

12. T. Angel: J Iron Steel Inst, Formation of martensite in austenitic stainless steel - Effects of deformation, temperature and composition. 177: p. 165-174. (1954).

13. G. Biallas, A. Piotrowski, D. Eifler: FFEMS, Cyclic stress-strain, stress-temperature and stress-electrical resistance response of $\mathrm{NiCuMo}$ allyed sintered steel. 18: p. 605-615, (1995).

14. A. B. Spierings, G. Levy: SFF Symposium, Comparison of density of stainless steel $316 \mathrm{~L}$ parts produced with selective laser melting using different powder grades. (2009).

15. C. Kamath, B. El-dasher, G. F. Gallegos, W. E. King, A. Sisto: Int J Adv Manuf Technol, Density of additively-manufactured, 316L SS 
parts using laser powder-bed fusion at powers up to $400 \mathrm{~W}$. 74: p. 65-78. (2014).

16. P. Ganesh, R. Kaul, G. Sasikala, H. Kumar, S. Venugopal, P. Tiwari, S. Rai, R. C. Prasad, L. M. Kukreja: Metallogr Microstruct Anal, Fatigue Crack Propagation and Fracture Toughness of Laser Rapid Manufactured Structures of AISI 316L Stainless Steel. 3: p. 3645, (2014).

17. O.H. Basquin: ASTM proceedings: The exponential law on endurance tests. 10: p. 625630, (1910).

18. J. Morrow: ASTM Int, Cyclic plastic strain energy and fatigue of metals. STP 378: p. 4587, (1964).

19. A. Grigorescu, P.-M. Hilgendorff, M. Zimmermann, C.-P. Fritzen, H.-J. Christ: Adv Mat Res, Effect of geometry and distribution of inclusions on the VHCF properties of a metastable austenitic stainless steel. 891-892: p. 440-445, (2014).

20. A.C. Grigorescu, P.-M. Hilgendorff, M. Zimmermann, C.-P. Fritzen, H.-J. Christ: Int J Fatigue, Cyclic deformation behavior of austenitic $\mathrm{Cr}-\mathrm{Ni}$-steels in the $\mathrm{VHCF}$ regime: Part I - Experimental study. 93: p. 250-260, (2016).

21. J. Günther, D. Krewerth, T. Lippmann, S. Leuders, T. Tröster, A. Weidner, H. Biermann, T. Niendorf: Int J Fatigue, Fatigue life of additively manufactured Ti-6Al-4V in the very high cycle fatigue regime. 94: p. 236-245, (2017). 